\title{
Modelo experimental de tumor na cavidade oral de ratos com carcinossarcoma de Walker $256^{1}$
}

Experimental model of Walker 256 carcinosarcoma developed in the oral cavity of rats

\author{
Ana Paula Negreiros Nunes Alves ${ }^{2}$, Rafael Cardoso Guedes ${ }^{3}$, Letícia Veras Costa- \\ Lotufo $^{4}$, Maria Elisabete Amaral de Moraes ${ }^{4}$, Cláudia do Ó Pessoa ${ }^{4}$, Francisco Valdeci \\ Almeida Ferreira ${ }^{5}$, Manoel Odorico de Moraes ${ }^{4}$
}

1. Trabalho realizado no Laboratório de Oncologia Experimental do Departamento de Fisiologia e Farmacologia da Faculdade de Medicina da Universidade Federal do Ceará (UFC).

2. Professora Assistente do Departamento de Clínica Odontológica da Faculdade de Odontologia, Farmácia e Enfermagem da UFC.

3. Bolsista de Iniciação Científica, PI-BIC da UFC.

4. Professora Adjunta do Departamento de Fisiologia e Farmacologia da Faculdade de Medicina da UFC.

5. Professor Doutor, PROPAP, Faculdade de Medicina da UFC.

\section{RESUMO}

OBJETIVO: Estabelecer um modelo experimental de desenvolvimento tumoral na cavidade oral de ratos, permitindo, assim, o estudo da osteólise induzida pelo tumor nos ossos do complexo maxilomandibular como também nas estruturas dentais, através da caracterização histomorfológica da reabsorção óssea e dentária.

MÉTODOS: Uma suspensão de células tumorais $(0,1 \mathrm{~mL})$ do Carcinossarcoma de Walker 256, na concentração de $10^{6}$ células $/ \mathrm{mL}$ foi implantado na cavidade alveolar de ratos previamente aberta por exodontia. Os animais foram observados durante 12 (doze) dias consecutivos para determinação da curva de peso corpóreo, sendo posteriormente sacrificados e as mandíbulas removidas para exames radiográfico e histológico.

RESULTADOS: No exame radiográfico foi verificada área lítica, sem evidência de reparo, na região dos alvéolos. No exame microscópico foi identificada infiltração óssea, periférica e central, de pequenas células hipercromáticas e pleomórficas, com leve infiltrado inflamatório mononuclear associado e áreas de necrose. O índice de pega foi de $100 \%$.

CONCLUSÃO: O modelo animal de invasão óssea, do tumor de Walker na cavidade oral, possibilita a avaliação in vivo de drogas antitumorais e esquemas terapêuticos no tratamento do câncer bucal.

Descritores: Modelo de tumor da cavidade oral. Carcinossarcoma de Walker.

\begin{abstract}
PURPOSE: To estabilish an experimental model of tumor development in the oral cavity of rats, that would enable to study the tumor-induced autolysis in the maxillomandibular bone complex as well as of the dental structures, through histomorphological characterization of bone and dental resorption.
\end{abstract}

METHODS: Walker 256 carcinossarcoma cell suspension $\left(0,1 \mathrm{~mL}\right.$ containing $\left.10^{6} \mathrm{cell} / \mathrm{mL}\right)$ was implanted in the alveoli of first and second molars. The animals were observed during 
twelve consecutive days and the body weigth were determined. Later, the animals were sacrificed and their mandibles removed to radiographic and hystologic analysis.

RESULTS: The radiographic image demonstrated radioluscencies with poorly defined borders. Microscopic examination revealed the tumor infiltration into the peripheral and central regions of bone.The tumor was composed predominantly of small cells with hyperchromatic nuclei which were occasionally pleomorphic. Areas of necrosis were commonly seen and chronic inflammatory cell infiltration was variable. The index of tumor incidence was $100 \%$.

CONCLUSION: The animal model of bone invasion of Walker 256 tumor permits the evaluation in vivo of new chemotherapic drugs in the treatment of oral cancer.

Key words : Experimental model, oral cancer. Walker 256 carcinosarcoma.

\section{Introdução}

A incidência do câncer de boca é extremamente variável, sendo em muitas partes do mundo um problema de saúde pública. Ocorrem atualmente cerca de 262.000 óbitos por cânceres da cavidade oral e da faringe em todo mundo, dos quais $83 \%$ em países em desenvolvimento ${ }^{1}$.

Os carcinomas espinocelulares são as neoplasias orais mais freqüentes, constituindo cerca de 90\% dos casos, seguidos por outros carcinomas como os verrucosos e indiferenciados, e tumores de pequenas glândulas salivares, sarcomas e raramente, por melanoma maligno ${ }^{1}$. As principais causas das neoplasias são atribuíveis a influências ambientais, particularmente aquelas relacionadas ao estilo de vida. Neste contexto, o câncer de boca não é exceção, podendo ser induzido por uma combinação de fatores: hábitos pessoais, atividade profissional e região onde o indivíduo habita. A incidência do câncer de boca tem acompanhado os padrões de consumo de tabaco e de álcool há várias décadas. Além desses fatores, exposição a dietas pobres em frutas e vegetais, a agentes biológicos (papilomavirus humano-HPV; fungo Candida albicans), irritação mecânica crônica (uso de próteses mal adaptadas, ação de bordas cortantes dos dentes sobre a mucosa bucal), a radiações e má higiene oral podem ocasionar alterações epiteliais que tornam a mucosa oral mais vulnerável aos agentes carcinógenos ${ }^{2,3}$.

As neoplasias malignas dos ossos maxilares e mandibulares, primários ou metastáticos, são comparativamente raros, em relação aos tumores de tecidos moles. Porém, as reabsorções patológicas do osso alveolar vistas numa variedade de neoplasias malignas são severas e graves, levando a microfraturas precocemente, além de dores intensas e hipercalcemia ${ }^{3,4}$. Os osteoclastos desempenham papel importante na patogênese desta complicação ${ }^{4,5}$. A ativação e a manutenção do processo de reabsorção estão intimamente relacionadas com uma resposta imune humoral, além da inflamatória propriamente dita com a produção de citocinas e prostaglandinas ${ }^{6}$. A invasão dos vasos sanguíneos pelas células tumorais resulta em isquemia grave local, podendo assim, levar ao quadro de necrose coagulativa, contribuindo para a osteólise tumor-induzida ${ }^{7}$.

Além da reabsorção óssea, células tumorais de origem epitelial ou mesenquimal podem invadir a polpa dental e o ligamento periodontal dos dentes adjacentes à área da neoplasia. As células responsáveis pela reabsorção do cemento e da dentina são morfologicamente semelhantes aos osteoclastos, se não idênticas, porém os mecanismos pelos quais elas reabsorvem seus respectivos substratos são largamente incomuns ${ }^{6}$. Nas neoplasias malignas dos ossos maxilares podem acontecer pequenos graus de reabsorção dentária, porém observase, com maior freqüência deslocamento das unidades dentárias.

O tratamento do câncer de boca é particularmente mutilante, muitas vezes inabilitando o paciente para a reintegração familiar, social e profissional, temporária ou definitivamente. No 
esforço por procurar novas alternativas terapêuticas de diferentes fontes, várias técnicas têm sido estabelecidas. Modelos experimentais de câncer de boca são descritos na literatura utilizando a indução química pelo 7,12-dimetilbenzantraceno (DMBA) ${ }^{8,9,10}$, o transplante de células do carcinoma escamoso e do carcinoma adenóide cístico em camundongos imunodeprimidos $^{11}$ e o transplante das linhagens celulares Tu159, Tu167 e MDA 1986 de carcinomas espinocelulares ${ }^{12}$. Já os modelos de metástases ósseas na região maxilofacial são realizados através da injeção intra-cardíaca de células do câncer de mama de humanos ${ }^{13,14}$. Até o presente não há relato na literatura de um modelo de neoplasia maligna no osso mandibular utilizando o tumor 256 de Walker, apesar deste já ter sido inoculado experimentalmente por diferentes vias com índices de pega variáveis ${ }^{15}$. O tumor Walker 256 é um carcinossarcoma de origem espontânea de glândula mamária de rata e tem comportamento biológico agressivo, sendo localmente invasivo e com alto poder de metástase por via linfática e hematogênica. Neste trabalho foi desenvolvido um modelo de tumor na cavidade oral de ratos com células do carcinossarcoma de Walker 256, o que permitiu um estudo dos efeitos diretos dos tumores líticos nos ossos do complexo maxilomandibular e nas estruturas dentárias.

\section{Métodos}

\section{Animais e células tumorais}

Foram utilizados 31 (trinta e um) ratos Wistar, fêmeas, 130-200 gramas, do Biotério Central da Universidade Federal do Ceará (UFC) e todos os esforços possíveis foram utilizados para minimizar o sofrimento e o número dos mesmos. Os animais foram mantidos no Laboratório de Oncologia Experimental (LOE) do Departamento de Fisiologia e Farmacologia da UFC, abrigados a $24^{\circ} \mathrm{C}$ em ciclo luz-escuro de 12 horas e com acesso a água e alimento ad libitium. As células tumorais usadas foram do Carcinossarcoma Walker 256, mantido em laboratório por inoculações intramusculares sucessivas na coxa direita de ratos Wistar. No $7^{\circ}$ ou $8^{\circ}$ dia de inoculação das células do tumor Walker, os animais são sacrificados para retirada do tumor e em seguida preparada uma suspensão de células com $10^{6}$ células $/ \mathrm{mL}$. A viabilidade das células tumorais foi examinada pelo teste de exclusão com azul de tripan em todos os experimentos.

\section{Técnica de implantação tumoral}

Todos os animais $(\mathrm{n}=31)$ foram anestesiados por via intraperitoneal com Hidrato de cloral a $10 \%$ para exodontia dos primeiros e segundos molares inferiores direitos. Com as cavidades alveolares abertas, foi implantado em 20 (vinte) animais $0,1 \mathrm{~mL}$ de suspensão de células do tumor de Walker. Testes pilotos foram realizados para determinação da quantidade de células que pudesse demonstrar $100 \%$ de pega do tumor na mandíbula de ratos. Posteriormente, os alvéolos foram suturados utilizando-se fio de sutura Vycril 6-0. O grupo de animais que não recebeu o tumor $(\mathrm{n}=11)$ foi submetido apenas ao procedimento de exodontia e sutura. Em seguida, os animais foram colocados na gaiola, permanecendo sob supervisão até o retorno completo da anestesia, quando retornaram ao Biotério.

Os animais foram observados diariamente por um período de 12 (doze) dias, sendo pesados nos dias $2^{\circ}, 4^{\circ}, 6^{\circ}, 8^{\circ}, 10^{\circ}$ e $12^{\circ}$ após inoculação do tumor na cavidade oral.

Ao longo do experimento 08 (oito) animais do grupo tumor chegaram a óbito, tanto em consequiência do ato cirúrgico como devido ao desenvolvimento do tumor, visto ser o Carcinossarcoma de Walker uma neoplasia maligna de alta agressividade. Em um outro grupo 
experimental verificou-se que a média de sobrevida dos animais inoculados com o tumor foi de 14,25 dias (resultado não mostrado).

Ao final do $12^{\circ}$. (décimo segundo) dia, os animais foram sacrificados e as mandíbulas removidas. As mesmas foram fixadas em Formol a $10 \%$ por $24 \mathrm{~h}$. As mandíbulas foram radiografadas pelo Sistema de Radiografia Odontológica. Após o registro radiográfico, foi procedida a macroscopia das peças cirúrgicas, e a parte mole do tumor foi separada da mandíbula. A mandíbula foi descalcificada por $24 \mathrm{~h}$ com Ácido Nítrico a $10 \%$. Posteriormente, todo o material da parte mole e da mandíbula foi encaminhado à histopatologia para confecção das lâminas pela coloração de hematoxilina- eosina ( HE ).

\section{Exame radiográfico}

As mandíbulas dos dois grupos foram radiografadas em aparelho de Rx odontológico para tomadas periapicais (Planmeca Prostyle Intra). O tempo de exposição ficou estabelecido do seguinte modo: para os animais do grupo sem tumor 0,08 segundos e para os animais do grupo com tumor 0,10 segundos. Foram utilizadas películas radiográficas periapicais e a revelação de todas as tomadas foi feita em processador automático(A/T 2000M Airtechniques, inc) com tempo médio de 5 (cinco) minutos.

\section{Análise histopatológica}

As lâminas histológicas foram confeccionadas utilizando-se a coloração de rotina pela hematoxilina-eosina e, a análise histopatológica foi realizada com auxílio de microscópio óptico, sendo avaliados os seguintes critérios: infiltração tumoral , central e periférica, necrose tecidual induzida pelo tumor, presença de osteoclastos e envolvimento da unidade dentária adjacente.

\section{Análise estatística}

A comparação do peso corpóreo entre o grupo 1 (sem tumor) e aquele que recebeu tumor (grupo 2) foi feita pelo teste $t$-Student com nível de significância de $0,1 \%$ e $5 \%$.

\section{Resultados}

Os animais do grupo 1 (sem tumor), que foram submetidos apenas as exodontias dos primeiros e segundos molares inferiores do lado direito sem inoculação de células tumorais, apresentaram uma discreta perda de peso nos primeiros dois dias, e após o quarto dia voltaram a ganhar peso (Figura 1).

Enquanto que os animais do grupo 2 (tumor) submetidos as exodontias seguidos de implantação do tumor de Walker, perderam peso nos dois primeiros dias, ganharam no quarto dia e entre o sétimo e oitavo dia após inoculação do tumor voltaram a perder peso, diferindo significativamente do Grupo 1 (Figura 1).

Ao exame macroscópico, o tumor de tecidos moles apresentava coloração vinhosa, de consistência firme e elástica, a qual invadia espaços musculares e glândulas salivares, o que confirmou a implantação de células tumorais na mandíbula. 


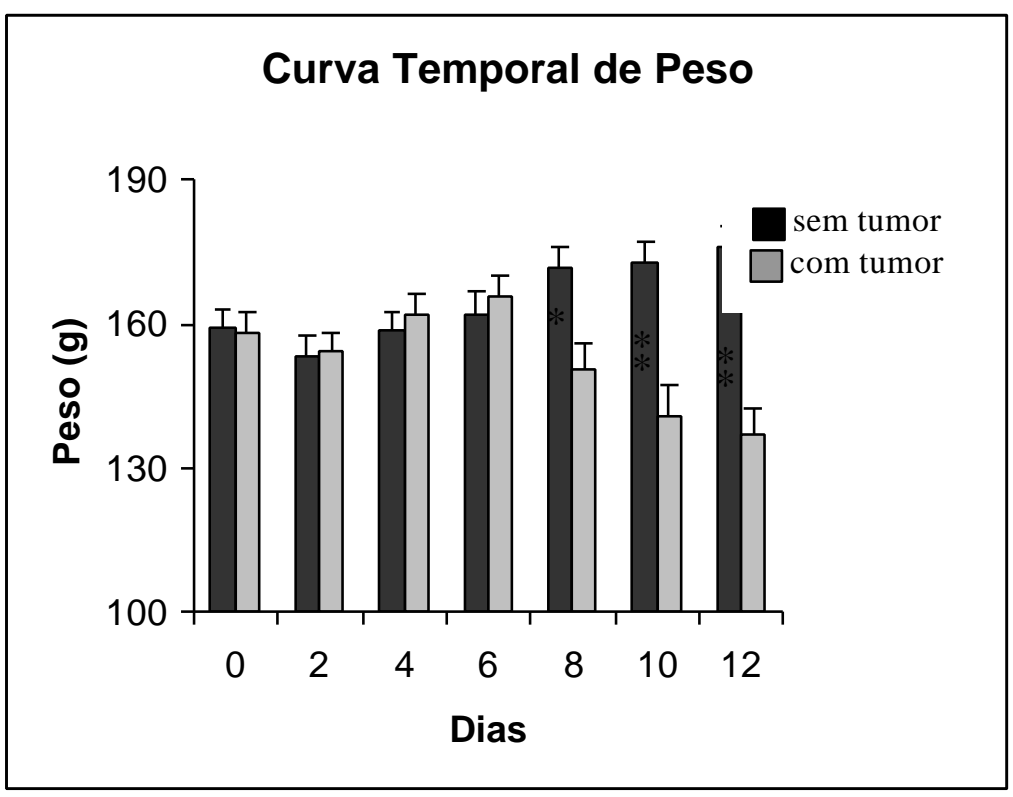

FIGURA 1 - Curva temporal média dos pesos corpóreos dos animais do grupo 1 (sem tumor) e do grupo 2 (com tumor), a cada dois dias após inoculação do tumor durante 12 dias.Os dados foram apresentados sob forma de média \pm EPM. A análise estatística foi feita utilizandose teste $t$ - Student, com $\mathrm{p}<0,001(* *)$ e $\mathrm{p}<0,05(*)$.

O exame radiográfico do grupo 1 (sem tumor) revelou área radiopaca, e por vezes radiotransparente, com visualização de traves ósseas.(Figura 2).

A

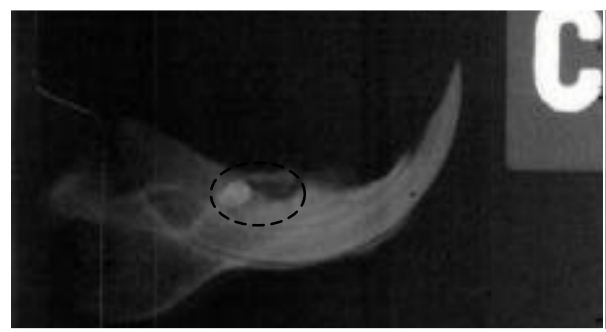

B

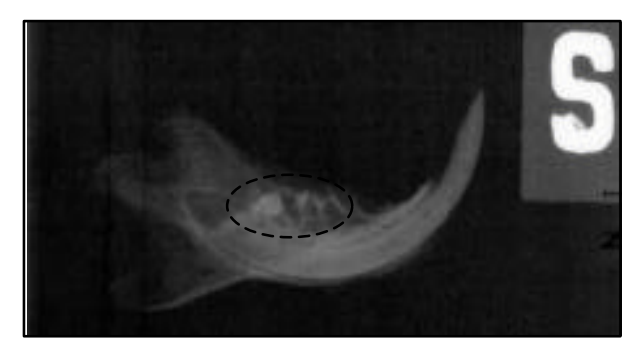

FIGURA 2 - Radiografia periapical da mandíbula direita. A) Área radiopaca na região da exodontia dos $1^{\circ}$ e $2^{\circ}$ MID, sugerindo cicatrização óssea. B) Septos ósseos radiopacos mostrando integridade dos alvéolos.

Os animais do grupo 2 inoculados com o tumor de Walker apresentaram área lítica difusa sem radiotransparência, que se estendia até a região do terceiro molar mantido na área (Figura 3). 
A)

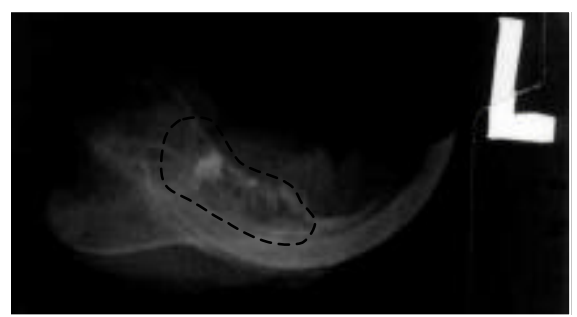

B)

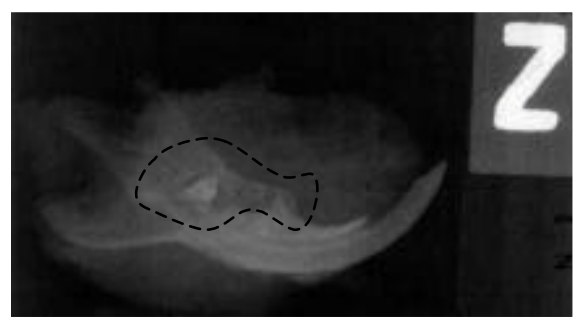

FIGURA 3 - Radiografia periapical da mandíbula direita. A) Área radiolúcida na região das exodontias, estendendo-se ao $3^{\circ}$ MID. B)Área lítica na mandíbula, sem evidência de reparo ósseo.

A principal evidência das alterações ósseas induzidas pelo tumor foi confirmada pela análise histopatológica. Ao exame microscópico do tumor das partes moles foi visualizado neoplasia mesenquimal maligna caracterizada por discreta anisocariose, sendo as células pequenas, redondas, de contorno nuclear irregular, cromatina frouxa e nucléolo evidente (Figura 4A). As células se dispunham frouxamente com tendência a arranjo alveolar e com largas áreas de necrose de coagulação. O tumor apresentou um elevado índice mitótico, chegando a 20 (vinte) mitoses em 10 (dez) campos microscópicos. Em relação a análise microscópica do tecido ósseo, verificou-se a presença de células com o mesmo padrão morfológico descrito acima, as quais infiltravam o osso centralmente e perifericamente (Figura 4B). Áreas de necrose de coagulação também estavam presentes (Figura 4C) e alguns osteoclastos foram visualizados. A unidade dentária mantida na região do tumor não apresentou nenhuma alteração histológica (Figura 4D). No grupo 1 (sem tumor) encontramos áreas de fibrose, osso secundário normal e medula óssea vermelha preservada caracterizando reparo ósseo. 

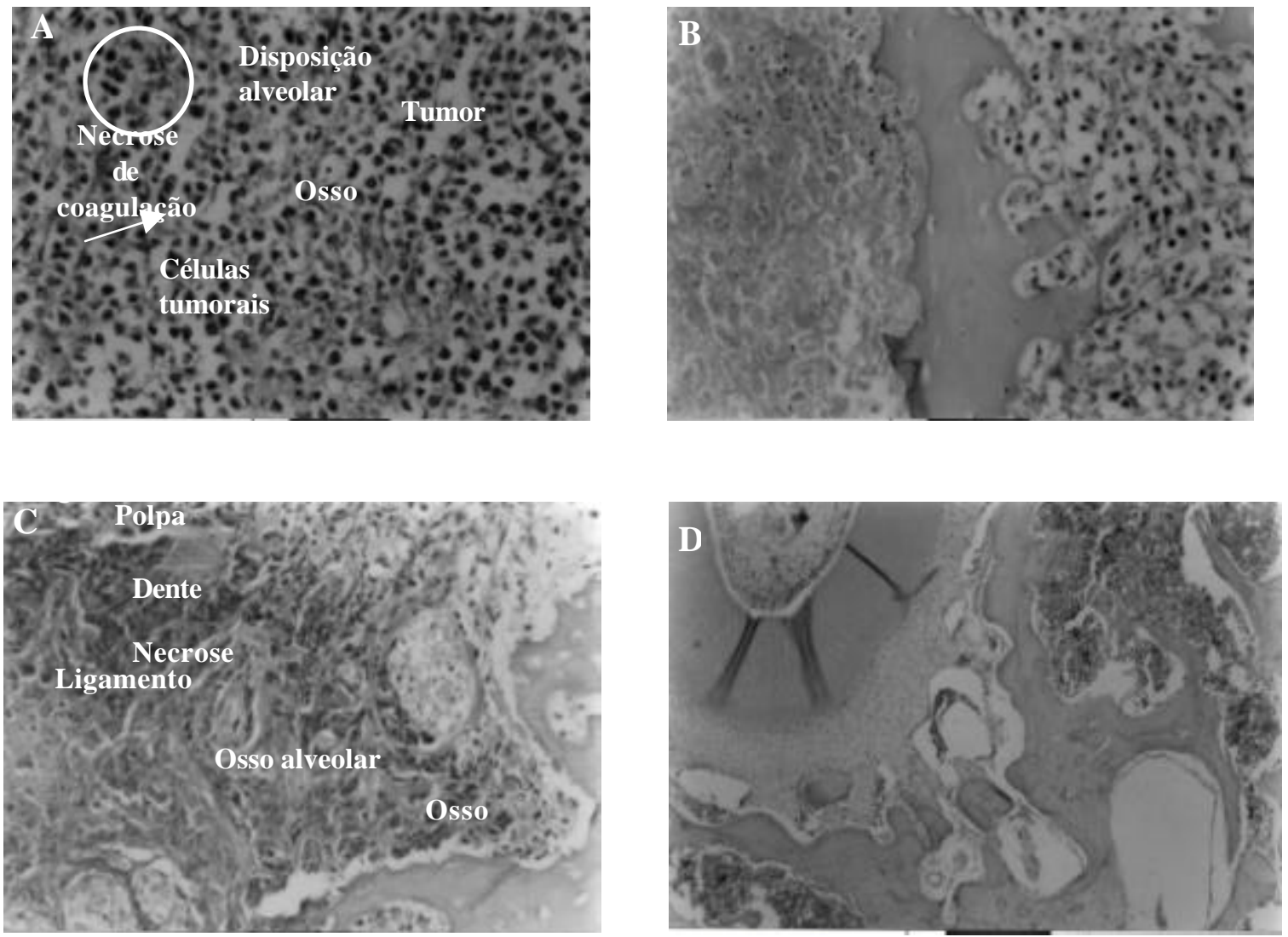

FIGURA 4 - Fotomicrografias da mandíbula e estruturas anexas. A) Corte histológico mostrando neoplasia maligna constituída por pequenas células hipercromáticas em arranjo alveolar. HE 10x. B) Células neoplásicas hipercromáticas infiltrando o osso com área de necrose de coagulação à direita HE 20x. C) Extensa área de necrose óssea.HE 20x. D) Unidade dentária sem alterações histológicas HE 4x.

\section{Discussão}

Em relação ao peso dos animais, ambos os grupos perderam peso nos primeiros dias. Essa perda inicial foi decorrente do processo cirúrgico das exodontias, já que as mesmas deixam alvéolos abertos, dificultando a alimentação. À medida que a cicatrização e o reparo ósseo foram acontecendo, a alimentação foi restabelecida e conseqüentemente o ganho de peso. Este comportamento foi observado nos dois grupos, com e sem tumor.

Os animais inoculados com tumor voltaram a perder peso a partir do oitavo dia. Este fato, provavelmente, aconteceu em conseqüência do crescimento tumoral, uma vez que, havia evidência macroscópica do tumor nos tecidos moles adjacentes ao osso mandibular no oitavo dia.

Evidência de invasão óssea do tumor foi inicialmente verificada através dos exames radiográficos que mostraram área lítica ( radiolúcida ) na mandíbula direita dos animais inoculados. A imagem radiográfica sugestiva de cicatrização óssea é dada por radioluscência que pode apresentar áreas com maior ou menor radiodensidade ${ }^{3}$, dependendo da etapa do 
processo de reparo. Todos os animais do grupo 1 ( sem tumor ) apresentaram radiopacidade, em graus variados, indicando cicatrização óssea em evolução. Além disso, em alguns casos visualizaram-se trabéculas ósseas preservadas exibindo maior densidade do que a das áreas circunjacentes, sugerindo integridade das estruturas ósseas remanescentes.

A análise microscópica das mandíbulas, tanto das partes moles quanto do osso, demonstrou a presença de células tumorais anaplásicas, com elevado índice mitótico, corroborando o diagnóstico da neoplasia maligna implantada. A invasão óssea pelas células tumorais foi então confirmada, sendo possível verificar necrose de coagulação e ninhos de osteoclastos. As áreas de necrose de coagulação presentes em todas as amostras (partes moles e tecido ósseo) sugerem morte hipóxica das células tumorais, provavelmente em conseqüência de infiltração vascular ${ }^{7}$. Sabe-se que os osteoclastos desempenham importante papel na destruição óssea tumor-induzida ${ }^{4,5}$. Portanto deve ser objeto de investigação futura se, neste modelo , a lise óssea observada também aconteceu por esta via ou em associação com o mecanismo da morte hipóxica das células.

A unidade dentária não apresentou nenhum grau de reabsorção nem invasão pulpar, demonstrando que as células do Carcinossarcoma de Walker 256 não causam nenhuma alteração sobre o dente.

Desse modo, verifica-se que o modelo proposto de inoculação do Carcinossarcoma de Walker na mandíbula de ratos é capaz de reproduzir formas osteolíticas de infiltração óssea sem reabsorção das raízes dentárias. Um aspecto importante relacionado ao câncer da região oral e maxilofacial, é que os tumores primários são freqüentemente adjacentes a estruturas ósseas. Porém, existem poucos modelos experimentais de invasão óssea in vivo na região orofacial. Já são descritos na literatura modelos experimentais de metástases para o osso mandibular a partir de injeção intracardíaca de células tumorais ${ }^{13,14}$. Contudo, diferenças no microambiente ósseo e a presença de dentes e outras estruturas anatômicas da cavidade oral podem exercer um papel importante, alterando o desenvolvimento das metástases ósseas. Além disso, as células tumorais podem sofrer metástases para as glândulas adrenais e mais raramente para outros órgãos, como o pulmão, fígado e cérebro, levando o animal, rapidamente, a um quadro grave de caquexia e morte ${ }^{13}$.

\section{Conclusões}

O modelo de implantação do tumor carcinossarcoma Walker 256 na cavidade oral é eficiente, tem reprodutibilidade e apresenta um índice de pega de $100 \%$. Os dentes localizados próximos ao tumor não apresentam nenhum grau de reabsorção, permanecendo íntegros, demonstrando o não envolvimento da unidade dentária por esta linhagem de células tumorais. Este modelo irá ser útil para o estudo de métodos alternativos na terapêutica do tratamento do câncer de boca com invasão óssea, tendo desse modo estabelecido uma nova linha de pesquisa no Laboratório de Oncologia Experimental (LOE) - UFC.

\section{Referências}

1. Parise Jr., O. Câncer de boca: aspectos básicos e terapêuticos. São Paulo: SARVIER; 2000.

2. Kowalski LP, Dib LL, Ikeda MK, Adde C. Prevenção, diagnóstico e tratamento do câncer bucal. Hospital do Câncer \& Associação Paulista de Cirurgiões dentistas. São Paulo: Frôntis Editorial; 1999.

3. Regezi JA, Sciubba J. Oral pathology clinical-pathologic correlations. 3ed. Philadelphia: WB. Saunders Company; 1999.

4. Kurth AA, Müller R. The effect of an osteolytic tumor on the three-dimensional trabecular bone morphology in an animal model. Skeletal Radiol 2001; 30:94-8.

5. Kurth AA, Kim SZ, Sedlmeyer F, Bauss F, Shea M. Ibandronate treatment decreases the effects of tumor-associeted lesions on bone density and strength in the rat. Bone 2002;30:1. 
6. Pierce A. Celular mechanisms in tooth and bone resorption. Department of Oral Pathology. Sweden; 1988.

7. Cotran R, Kumar V, Robbins SL. Patologia estrutural e funcional. 4ed. Rio de Janeiro: Guanabara Koogan; 1991.

8. Lee SK, Park SC, Chi JG, Sakamato F, Shrestha P, Mori M. Expression of tenascin in hamster buccal pouch mucosa during experimental carcinogenesis. Eur J Cancer B Oral Oncol 1995; 31(B):188-92.

9. Sacks PG. Cell, tissue and organ culture as in vitro models to study the biology of squamous cell carcinomas of head and neck. Cancer Metastasis Rev 1996; 15(1):27-51.

10. Nauta JM, van Leengoed HL, Witjes MJ, Nikkels PG, Star WM, Vermy A, Roodenburg JL. Photofrin-mediated photodynamic therapy of chemically-induced premalignant lesions and squamous cell carcinoma of the palatal mucosa in rats. Int J Oral Maxillofac Surg 1997; 26(3):22331.

11. Umeda M, Yokoo S, Komori T, Nishimatsu N, Shibuya Y, Fujioka M. Experimental model of invasion and metastasis by orthotopic transplantation of oral squamous and adenoid carcinomas into tongue of nude mice. Br J Oral Maxillofac Surg 2001; 39(5):376-80.

12. Meyers JN, Holsinger FC, Bekele BN, Li E, Jasser SA, Killion JJ, Fidler IJ. Targeted molecular therapy for oral cancer with epidermal growth factor receptor blockade: a preliminary report. Arch Otolaryngol Head Surg 2002; 128(8):875-9.

13. Sasaki A, Yoneda T, Terakado N, Alcalde RE, Suzuki A, Matsumura T. Experimental bone metastasis model os the oral and maxillofacial region. Anticancer Res 1998; 18(3A):1579-84.

14. Sasaki A, Nishiyama A, Alcalde RE, Lim DJ, Mese H, Nakayama S, Yokoyama S, Matsumura T. Effects of bisphosphonate on experimental jaw metastasis model in nude mice. Oral Oncol 1999; 35(5):523-9.

15. Oliveira PFM, Henriques IA, Rodrigues Filho F, Almeida PRC, Moraes MO. Estabelecimento de um modelo de tumor experimental pela inoculação do tumor de Walker no estômago de rato. Acta Cir Bras 1998; 13(4): 243-8.

\section{Agradecimentos}

À Clínica Radiológica Prof. Perboyre Gomes Castelo pelo suporte científico e técnico que possibilitou as análises radiográficas do presente trabalho.

Ao CNPq pelo auxílio financeiro.

Correspondência:

Prof. Dr. Manoel Odorico de Moraes

Departamento de Fisiologia e Farmacologia

Rua Coronel Nunes de Mello, 1127

60340-370 Fortaleza - Ceará

Odorico@ufc.br

Recebimento: 22/03/2004

Revisão: 19/04/2004

Aprovação: 06/05/2004

Conflito de interesse: nenhum

Fonte de financiamento: $\mathrm{CNPq}$

\section{Como citar este artigo:}

Alves APNN, Guedes RC, Costa-Lotufo LV, Moraes MEA, Pessoa CO, Ferreira FVA, Moraes MO. Modelo experimental de tumor na cavidade oral de ratos com carcinossarcoma de Walker $256^{1}$. Acta Cir Bras [serial online] 2004 Jul-Ag;19(4). Disponível em URL: http://www.scielo.br/acb [também em CD-ROM]. 